\title{
Combining Adoptive Treg Transfer with Bone Marrow Transplantation for Transplantation Tolerance
}

\author{
Nina Pilat ${ }^{1} \cdot$ Nicolas Granofszky $^{1} \cdot$ Thomas Wekerle $^{1}$
}

Published online: 4 November 2017

(C) The Author(s) 2017. This article is an open access publication

\begin{abstract}
Purpose of Review The mixed chimerism approach is an exceptionally potent strategy for the induction of donorspecific tolerance in organ transplantation and so far the only one that was demonstrated to work in the clinical setting. Regulatory $\mathrm{T}$ cells (Tregs) have been shown to improve chimerism induction in experimental animal models. This review summarizes the development of innovative BMT protocols using therapeutic Treg transfer for tolerance induction.

Recent Findings Treg cell therapy promotes BM engraftment in reduced conditioning protocols in both, mice and nonhuman primates. In mice, transfer of polyclonal recipient Tregs was sufficient to substitute cytotoxic recipient conditioning. Treg therapy prevented chronic rejection of skin and heart allografts related to tissue-specific antigen disparities, in part by promoting intragraft Treg accumulation.

Summary Adoptive Treg transfer is remarkably effective in facilitating BM engraftment in reduced-intensity protocols in mice and non-human primates. Furthermore, it promotes regulatory mechanisms that prevent chronic rejection.
\end{abstract}

Keywords Regulatory Tcells · Bone marrow transplantation · Mixed chimerism · Treg therapy $\cdot$ Transplantation tolerance

This article is part of the Topical Collection on Immunology

Thomas Wekerle

Thomas.Wekerle@meduniwien.ac.at

Section of Transplantation Immunology, Department of Surgery, Medical University of Vienna, Waehringer Guertel 18-20, 1090 Vienna, Austria

\section{Introduction}

The age-long history of organ transplantation is a story of miracles, myths, and science fiction until six decades ago, when the first successful kidney transplant was performed between identical twins [1]. Some years later, the development of the first immunosuppressive drugs paved the way for the success story of clinical organ transplantation and soon it became the treatment of choice for end-stage organ diseases. Current immunosuppressive drug regimens succeed in preventing acute rejection and improve short-time survival; however, long-term outcomes did not improve to the same degree [2, 3]. Moreover, chronic use of immunosuppressive drugs is associated with increased morbidity and mortality in transplant recipients, while these medications often fail to prevent the development of chronic rejection, which is a leading cause of graft loss [4]. Induction of donor-specific immunological tolerance would not only obviate the need for life-long immunosuppression, therefore improving patient survival, but also eliminate the risk of late graft loss due to chronic rejection and preserve overall protective immunity.

Regulatory T cells (Tregs) are not only the key mediators of self-tolerance, preventing fatal autoimmunity [5], but are also recognized to play a critical role in the induction and maintenance of tolerance after organ transplantation in spontaneously tolerant patients [6].

\section{Induction of Tolerance}

Tolerance per se is defined by as immunological nonreactivity to a specific antigen while maintaining reactivity to others, in the field of transplantation this means "the absence of graft rejection without the (chronic) use of immunosuppressive drugs" [7]. Extensive research on the way to find the "Holy Grail" of tolerance led to the development of 
numerous protocols for intentional tolerance induction approaches in rodent models, including functional deletion [8], costimulation blockade [9], non-depleting antibodies [10,11], active regulatory mechanisms including Treg expansion [12], and infusion [13] or the establishment of mixed chimeras via BMT [14]. While several of these protocols yielded excellent results in mice, most of them failed when being translated into the non-human primate (NHP) system [15•].

Although mouse models have been an invaluable tool for uncovering the basic principles of allorecognition and defined strain combinations as well as genetically modified mice allowed dissection of individual pathways in transplantation immunology, there are major limitations when it comes to translation from mice to men [16]. A major hurdle for translation of murine models in the clinic is the high frequency of alloreactive memory cells found in adult humans, in contrast to young laboratory mice which are kept under SPF conditions [17]. The use of "dirty" mice would be one step towards mimicking a highly experienced immune system which may interfere with tolerance induction [18••]. Also, the use of mouse strain combinations affects outcome as some are easier to tolerize than others [19], in particular if they lack minor antigen disparities, which is not realistic in the clinical setting and has been shown to euphemize long-term graft survival [20••, 21].

Another barrier for translation of tolerance approaches from mice to humans is the limited availability of pharmaceuticals. Blockade of the CD40:CD40L pathway using an anti$\mathrm{CD} 40 \mathrm{~L} \mathrm{mAb}$ (MR1) was the most successful and promising approach in murine models. It is the backbone of many nonmyeloablative mixed chimerism protocols, obviating the need for global $\mathrm{T}$ cell depletion and thymic irradiation [22]. A clinical phase I/II trial using humanized anti-CD40L antibody BG9588 had to be ended prematurely because of severe thromboembolic complications [23]. Another humanized anti-CD40L (clone hu5C8) led to severe thromboembolic complications in NHP studies [24]. Consequently, further clinical trials were put on hold [25]. Several clones of antiCD40 have been tested as an alternative strategy to block CD40:CD40L interactions, some of them showing promising results in the prolongation of allograft survival in NHPs [26]. One of them, namely, ASKP1240, has recently been assessed for safety and efficacy in a phase II trial in kidney transplantation (ClinicalTrials.gov Identifier: NCT01780844). Currently, next-generation anti-CD40L mAbs devoid of the Fc-mediated toxicity are under development and offer promise for clinical application [27].

Preclinical animal studies using knockout, immunodeficient, or TCR transgenic strains are definitely important for mechanistic understanding of allorecognition and signaling pathways. However, for the development of tolerance strategies, more realistic approaches using stringent strain combinations including minor antigen disparities, housing in non-SPF environment and clinically available pharmaceuticals are warranted.

\section{Tolerance Induction Through Mixed Chimerism}

Mixed chimerism denotes a state of co-existence of donor and recipient hematopoietic cells after allogeneic BMT in a preconditioned recipient [28]. Induction of persistent mixed chimerism has been readily achieved in murine models using numerous different strategies, and a number of protocols with reduced recipient conditioning could be developed. However, these protocols could not be readily translated into NHPs or humans as the immunologic barrier for engraftment of allogeneic BM is higher than in rodents. While permanent multilineage mixed chimerism across MHC barriers can be easily induced in rodents, the situation in NHPs and humans is more difficult. In the clinical setting, intense recipient preconditioning leads to the development of full chimerism which is undesirable in the organ transplantation setting as associated with the risk of GVHD and immuneincompetence [29]. The outstanding difference between chimerism and other tolerance strategies is the induction of "central" tolerance via intrathymic deletion by negative selection [14]. Thus, utilizing a process critical for the maintenance of self-tolerance, the mixed chimerism approach is expected to be robust and permanent.

As current clinical protocols for HLA-mismatched BMT are not ready for widespread clinical application for non-lifethreatening diseases due to the toxicity related to recipient preconditioning and the risk of GVHD, a lot of effort has been made to develop "safer" BMT protocols. Considering the importance of regulatory mechanisms and the potency of Tregs to suppress allo-reactivity, adoptive Treg transfer has emerged as attractive possibility that might be the key to translating murine chimerism-based tolerance protocols to the clinic.

\section{A Role for Active Regulatory Mechanisms}

Physiological self-tolerance not only involves central deletion but also critically requires non-deletional mechanisms (e.g., regulation, anergy) in order to maintain peripheral tolerance as autoreactive clones can escape negative selection. Deficits in central or peripheral tolerance cause autoimmune disease or in terms of transplantation tolerance result in graft rejection. In protocols using myeloablative and $\mathrm{T}$ cell depleting conditioning regimens, non-deletional tolerance mechanisms play a minor or even dispensable role likely due to the fact that potentially alloreactive $T$ cells are destroyed at the time of BMT and high levels of intrathymic chimerism retain central deletion of newly developing allo-reactive T cells. Experiments employing reduced intensity BMT protocols have revealed the importance for regulatory mechanisms in the induction phase of tolerance when deletion of allo-reactive $\mathrm{T}$ cell clones is still incomplete [30]. Tolerance, but not chimerism, could be abrogated by early treatment with anti-CD25 suggesting an active role for $\mathrm{CD} 4^{+} \mathrm{CD} 25^{+}$ Tregs, even in the presence of hematopoietic donor cells. 
However, neither regulation through Tregs nor classical anergy appear crucial several months after BMT for the maintenance of tolerance in established chimeras [30]. In sharp contrast, regulatory mechanisms have been shown to be critical even late after BMT in settings devoid of cytotoxic recipient conditioning [20••, 31]. Although the creation of "space" in distinct stem cell niches by myelosuppressive treatments enhances BM engraftment, it has been shown to be dispensable and can be overcome by very high doses of BM [32,33], modulation of the immune system by targeting apoptosis [34], or adoptive Treg transfer [35]. Chimerism levels are generally lower in protocols without myelosuppression by irradiation or cytotoxic drugs; however, tolerance appears not linked to the degree of chimerism as long as it is stable and of multilineage nature. Interestingly, chimerism protocols relying on Tregs, and other regulatory mechanisms instead of deletional mechanisms only, have been shown to be superior in the prevention of chronic rejection $[20 \bullet \cdot, 36]$ and could alleviate GVHD [37॰]. This raises the question whether protocols involving intense recipient pre-conditioning preclude or at least aggravate regulatory tolerance mechanisms or if regulatory mechanisms need to be actively induced via adoptive cell transfer or other forms of immunomodulation. However, the latter explanation seems to be more likely as full immunological tolerance was also induced after BMT in protocols using various doses of TBI (up to 7 Gy) and adoptive Treg transfer [38-41]. The use of (clinically unrealistic) minor matched strain combinations and the absence of pathohistological examination of donor grafts in earlier reports of murine mixed chimerism protocols could have led to the underestimation of the importance of active regulatory mechanisms. However, recently, there have been numerous reports on "split tolerance" in chimeras [42] and it was acknowledged that chimerism and subsequent tolerance towards antigens of hematopoietic origin does not always equal full immunological tolerance towards (tissue-specific) minor antigens. Cells of hematopoietic origin were indeed shown to induce "passive tolerance" through mechanisms including apoptosis and anergy, but active regulatory mechanisms are obviously required to control anti-donor reactivity in the same manner as they are required to maintain self-tolerance [43].

\section{Tolerance in the Clinics: More than Just Chimerism}

The original observation that the chimerism approach is successful in the clinical setting derives from numerous case reports in which conventional BMT recipients (most of them suffering from hematological malignancies) subsequently received an organ from the same donor for unrelated treatment of organ failure [44]. In such cases, organs are accepted without (chronic) conventional immunosuppression, even in an HLA donor-recipient setting [45]. Nevertheless, to date, only three centers have prospectively tested BMT for tolerance induction in the clinic, systematically translating findings from preclinical animal models to clinical kidney transplantation: the Massachusetts General
Hospital/Harvard Medical School [46-47, 48••], the Stanford University School of Medicine [49-51], and the Northwestern Memorial Hospital/University of Louisville [52-54], all of them located within the USA (recently reviewed in detail in [55]).

The MGH approach is based on decade-long studies in mice and NHPs and initially tested in patient who suffered from coincidental multiple myeloma and end-stage kidney disease, legitimating BMT and cytotoxic recipient conditioning [56-59]. The initial proof-of-principle study included seven patients who received simultaneous kidney and BMT from HLA matched donors. All of them developed chimerism; however, one case of acute GVHD and two cases of chronic GVHD have been observed. Sustained renal allograft tolerance was achieved although some cases were complicated by myeloma recurrence [59]. The second patient cohort included 10 patients suffering from end-stage renal disease without concomitant hematological disease, receiving HLAmismatched kidney and BMT. Chimerism was initially induced in all patients but was only transient and lost after approximately $2-3$ weeks with no incidence for GVHD in any of the patients. Immunosuppression could be discontinued for a prolonged period of time in seven patients; three grafts have been lost due to rejection [48••]. Importantly, in the absence of persistent chimerism, regulatory mechanisms seem to play a major role in tolerance induction in these patients, although there was also evidence for (peripheral) clonal deletion of donor-reactive $\mathrm{T}$ cell clones [60 ${ }^{\bullet}$. Tregs have been shown to be enriched in peripheral blood [61••] and allograft biopsies [46] after combined kidney and BMT in tolerant patients; however, it is unclear whether this is due to clonal expansion, de novo generation in the thymus or the periphery, or selective advantage with regard to conditioning and BMT. Tregs showed no decrease in demethylation status of TSDR region which is related to stability and suppressor function; moreover, the majority of Tregs presented with memory phenotype by 2 weeks post-BMT. However, the mechanisms leading to indefinite allograft survival despite the loss of chimerism in some patients still have to be fully elucidated [62].

In contrast, in murine models, stable macrochimerism and sustained presence of discrete populations of donor APCs in the thymus is a pre-requisite for durable tolerance as it ensures intrathymic deletion of alloreactive T cells. Nevertheless, high levels of chimerism do not necessarily predict long-term allograft survival and donor $\mathrm{T}$ cell engraftment was shown to be critical for long-term tolerance [63]. Dissociation of hematopoietic chimerism and donor graft survival is referred to as "split tolerance" phenomenon. Although still incompletely understood, incomplete tolerance towards skin or solid organ allografts is triggered by tissue-specific antigens and does not involve direct allorecognition [64]. Studies in human renal transplantation patients and NHPs have clearly demonstrated that the situation is different and long-term allograft survival can be achieved with transient chimerism only $[46,65,66]$. 
Continued renal allograft survival in the absence of permanent chimerism suggests a dominant role for peripheral mechanisms in non-murine models. Whereas the liver has been uniformly recognized a "tolerogenic" organ and a sound percentage of operational tolerance was reported in liver allograft recipients, also, the kidney itself was shown to induce tolerance towards cardiac allografts in miniature swine models [67]. Likewise, in human tolerance studies, the kidney is suggested to be important for maintaining tolerance by peripheral, most likely regulatory mechanisms.

\section{Tregs for Tolerance Induction}

Cell therapy approaches using $\mathrm{CD} 4^{+} \mathrm{CD} 25^{+} \mathrm{FoxP}^{+}$Tregs for tolerance induction have been envisioned since the (re)discovery of these powerful suppressor cells more than two decades ago [68] and is currently investigated by researchers all over the globe. Some of the world's most renowned research institutes are collaboratively working on gaining insight into the immunomodulatory mechanisms, cell product development, and clinical trial management (e.g., onestudy.org).

The therapeutic potential of Tregs was underlined by numerous reports, showing potent effects in pre-clinical autoimmune and allo-transplantation models; however, in these reports, the use of lymphopenic hosts $[69,70]$ or TCR transgenic Tregs $[71,72]$ was necessary and only minor antigen disparities or single MHC mismatches could be tolerated, respectively. So far, Tregs have not been shown to induce skin graft tolerance across MHC barriers on their own in unmanipulated recipients with a polyclonal T cell repertoire. Moreover, Tregs with indirect antigen specificity are suggested to be required for the prevention of chronic allograft rejection [38, 72], exacerbating clinical implementation.

Although the hype has stagnated a little bit during the last years due to the realization of several hurdles associated with adoptive Treg therapy [73], a recent study reported on successful induction of allograft tolerance through infusion of regulatory cells in liver transplantation patients [74•]. Still, tolerance protocols relying exclusively on peripheral tolerance are in danger to be eventually overwhelmed by the continuous thymic output of donor-reactive T cells [75] or to be broken by extreme activation of the immune system, e.g., by severe infections [76] or by successive antigen challenges [77].

\section{Combining Chimerism and Adoptive Treg Transfer}

Given the potency of both approaches, combination of the mixed chimerism approach and adoptive Treg transfer seems to be the next logical step on the search for the holy grail of tolerance [78]. The proof of principle for the success of this combined approach was already given in several studies: coinfusion of Tregs with allogeneic BM was shown to promote BM engraftment $[40,41,79]$ in pre-conditioned mice and enabled the development of the first clinically relevant BMT protocol devoid of cytotoxic recipient conditioning [35]. Although several protocols for combined BMT/Treg infusions are published (see Table $1[35,36,38-41,79-84]$ ), there are still many open questions and concerns, precluding their immediate translation into the NHP setting and the clinics. Based on the experience in the murine setting [35], the first NHP protocol for chimerism and tolerance induced by the combination of BMT and therapeutic Treg transfer has recently been developed $[85 \cdot \bullet]$. Treg treatment led to the induction of multilineage chimerism which lasted longer than in all the previous NHP studies and which notably included the T cell lineage. Long-term donor kidney graft survival was achieved, even in the setting of delayed kidney transplantation. This NHP study provides a proof of principle that Treg cotransfer can promote BM engraftment and prevent allograft rejection. However, early CMV reactivation interfered with chimerism induction in some animals, necessitating further refinement of the protocol for translation into the clinics.

Most of the protocols with combined Treg and BMT are employing clinically achievable doses of allogeneic BM $\left(20 \times 10^{6}\right.$ which corresponds to $\approx 1 \times 10^{9}$ cells $\left./ \mathrm{kg}\right)$. Recipient preconditioning was non-myeloablative and consisted mostly of mild doses of irradiation and/or costimulation blockade targeting the CD40:CD40L or CD28:B7 pathway. Notably, Treg transfer was capable of obviating the need for recipient irradiation (or cytotoxic drug treatment), allowing for the first time engraftment of fully mismatched BM without myelosuppression [35]. Comparable numbers of Tregs were used in all murine protocols ranging from 0.5 to $5 \times 10^{6}$ cells. The most interesting and critical question is the source of Tregs (donor- vs recipient- vs third party-derived) and the need for specificity (polyclonal vs allo-/ donor-specific Tregs). Several groups reported that antigenspecific Tregs are more potent compared to a polyclonal Treg population in models with [79] or without BMT [72, 86, 87] and that indirect specificity is critical for the prevention of chronic allograft rejection $[13,38]$. However, most of these studies compared in vitro expanded alloantigen-specific Tregs which have been activated with IL-2 for several days to freshly sorted polyclonal Tregs. Indeed, whereas Treg activation is claimed to be antigen-specific, their suppressor function might not be, at least in in vitro assays [88]. This hypothesis is supported by the fact that in vitro-activated polyclonal Tregs are potent in promoting BM engraftment $[35,80]$ and the prevention of acute and chronic allograft rejection [36].

\section{Treg Conundrum: Less Chimerism, More Tolerance?}

We and others could previously show that therapeutic Treg treatment leads to engraftment of clinically realistic doses of $\mathrm{BM}$ and sustainable tolerance in stringent strain combinations $[35,38]$. Tolerance induced by Tregs was superior to other chimerism protocols, which failed to prevent chronic rejection 


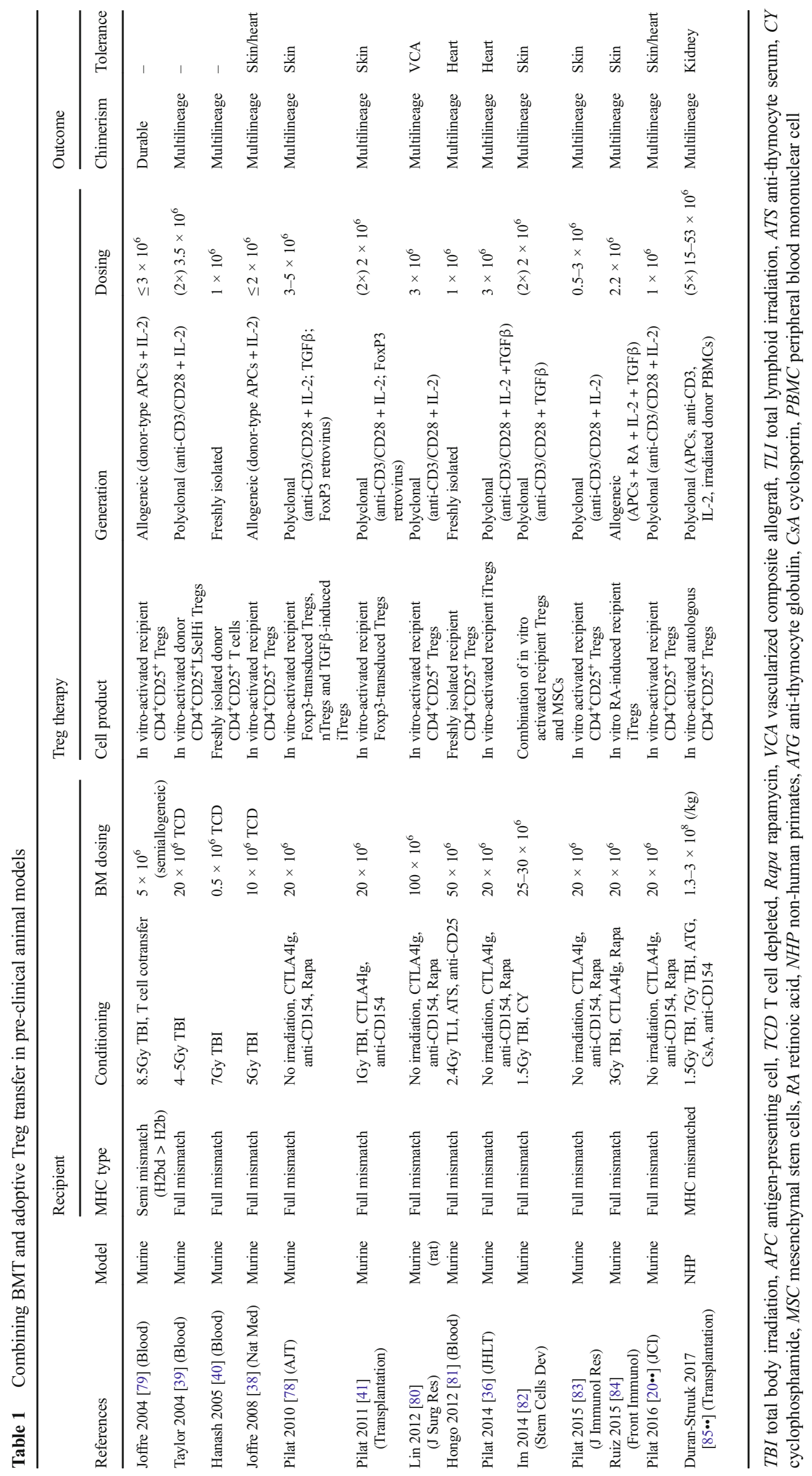


triggered by minor antigens; moreover, tolerance could be verified in primarily vascularized cardiac allografts and highly immunogenic skingrafts likewise. Both protocols were based on different conditioning regimens (irradiation vs costimulation blockade) and used different Treg populations (in vitro-activated polyclonal vs antigen-specific), highlighting the potency of Tregs in chimerism-based tolerance strategies. Unfortunately, both protocols are not ready for immediate clinical translation as either 5 Gy total-body-irradiation or costimulation blockade with anti-CD40L was utilized, so some fine-tuning is warranted.

In our "Treg-BMT" protocol, clinically, realistic numbers of BM and Tregs were infused into the recipient under the cover of costimulation blockade and a short course of rapamycin. Treg infusion is critical for BM engraftment and could not be replaced by IL2/anti-IL2 complex-based immunomodulation [89]. Importantly, the tolerance achieved using Tregs was superior to well-established BMT protocols using recipient TBI to allow BM engraftment $[21,22,36]$. The use of fully mismatched strain combinations revealed incomplete tolerance in non-myeloablative regimens relying primarily on deletional tolerance mechanisms [21]. Chimeras induced with low-dose irradiation presented with profound histopathologic signs of chronic rejection at the end of follow-up in both skin and heart allografts, which were shown be caused by minor antigen disparities. However, in sharp contrast, grafts from Treg-induced chimeras were devoid of chronic rejection $[35,36]$. Leucocyte infiltrates in the grafts of Tregtreated chimeras were enriched in $\mathrm{FoxP}^{+}$Tregs, which were shown to have an active role in the mediation of graft survival $[20 \bullet, 35]$. Our data suggest that adoptive Treg transfer not only allows BM engraftment and the induction of chimerism in the absence of cytotoxic recipient conditioning but prevents graft rejection mediated by minor antigens via linked suppression $[20 \bullet \bullet$. Thus, regulatory mechanisms due to adoptive Treg transfer maintain tolerance towards tissue-specific minor antigens of the donor via active intragraft regulation [20••]. Therapeutic Tregs transfer in the absence of substantial cytotoxic "danger-prone" host conditioning is therefore likely to allow for creation of a tolerogenic state involving "infectious tolerance"-like mechanisms that protect allografts from chronic rejection directed towards non-MHC tissue-specific antigens.

\section{Conclusion}

More than 60 years after Owen and Medawar's groundbreaking work on experimental tolerance induction by creation of mixed hematopoietic chimeras, tolerance has become a clinical reality only in a few highly selected recipients of living-donor kidney transplantation. Decades of intensive research in murine, swine, and NHP models led to the acknowledgement of peripheral regulatory mechanisms as critical factor for sustained allograft survival and the prevention of chronic rejection. Although peripheral regulation of (allo)immune responses is recognized as a complex network of multiple regulatory cell types, $\mathrm{CD} 4^{+} \mathrm{CD} 25^{+} \mathrm{FoxP}^{+}$Tregs have emerged as the most potent and important population in the maintenance of self- and allograft tolerance. The combination of the mixed chimerism approach with therapeutic Treg cell therapy has shown great potency in preclinical animal models in terms of both safety and efficacy. Treg treatment not only enabled tremendous decrease in recipient conditioning, a prerequisite for widespread clinical application, but also created genuine tolerance inhibiting chronic rejection of allografts. We think that combining the mixed chimerism approach and adoptive Treg transfer allows for implementation of complementary tolerance mechanisms in the recipient, therefore mimicking the complex system of self-tolerance.

Acknowledgements Open access funding provided by Medical University of Vienna.

\section{Compliance with Ethical Standards}

Conflict of Interest The authors declare that they have no conflict of interest.

Human and Animal Rights and Informed Consent This article does not contain any studies with human or animal subjects performed by any of the authors.

Open Access This article is distributed under the terms of the Creative Commons Attribution 4.0 International License (http:// creativecommons.org/licenses/by/4.0/), which permits unrestricted use, distribution, and reproduction in any medium, provided you give appropriate credit to the original author(s) and the source, provide a link to the Creative Commons license, and indicate if changes were made.

\section{References}

Papers of particular interest, published recently, have been highlighted as:

- Of importance

•- Of major importance

1. Barker CF, Markmann JF. Historical overview of transplantation. Cold Spring Harb Perspect Med. 2013;3(4):a014977. https://doi. org/10.1101/cshperspect.a014977.

2. Lamb KE, Lodhi S, Meier-Kriesche HU. Long-term renal allograft survival in the United States: a critical reappraisal. Am J Transplant. 2011;11(3):450-62. https://doi.org/10.1111/j.1600-6143.2010.03283.x.

3. Wekerle T, Segev D, Lechler R, Oberbauer R. Strategies for long-term preservation of kidney graft function. Lancet. 2017;389:2152-62.

4. Sellares J, de Freitas DG, Mengel M, Reeve J, Einecke G, Sis B, et al. Understanding the causes of kidney transplant failure: the dominant role of antibody-mediated rejection and nonadherence. 
Am J Transplant. 2012;12(2):388-99. https://doi.org/10.1111/j. 1600-6143.2011.03840.x

5. Kim JM, Rasmussen JP, Rudensky AY, Regulatory T. Cells prevent catastrophic autoimmunity throughout the lifespan of mice. Nat Immunol. 2007;8(2):191-7.

6. Pons JA, Revilla-Nuin B, Baroja-Mazo A, Ramirez P, MartinezAlarcon L, Sanchez-Bueno F, et al. FoxP3 in peripheral blood is associated with operational tolerance in liver transplant patients during immunosuppression withdrawal. Transplantation. 2008;86(10):1370-8. https://doi.org/10.1097/TP.0b013e318188d3e6.

7. Jr Auchincloss H. In search of the elusive Holy Grail: the mechanisms and prospects for achieving clinical transplantation tolerance. Am J Transplant. 2001;1(1):6-12.

8. Slavin S, Morecki S, Weigensberg M, Bar S, Weiss L. Functional clonal deletion versus suppressor cell-induced transplantation tolerance in chimeras prepared with a short course of total-lymphoid irradiation. Transplantation. 1986;41(6):680-7.

9. Larsen CP, Elwood, Alexander DZ, Ritchie SC, Hendrix R, Tucker-Burden $\mathrm{C}$, et al. Long-term acceptance of skin and cardiac allografts after blocking CD40 and CD28 pathways. Nature. 1996;381(6581):434-8.

10. Hutchings $\mathrm{P}, \mathrm{O}$ 'Reilly L, Parish NM, Waldmann H, Cooke A. The use of a non-depleting anti-CD4 monoclonal antibody to reestablish tolerance to beta cells in NOD mice. Eur J Immunol. 1992;22(7):1913-8. https://doi.org/10.1002/eji.1830220735.

11. Chong AS, Ma L, Yin D, Shen J, Blinder L, XiuLong X, et al. Nondepleting anti-CD4, but not anti-CD8, antibody induces long-term survival of xenogeneic and allogeneic hearts in alpha1,3galactosyltransferase knockout (GT-Ko) mice. Xenotransplantation. 2000;7(4):275-83.

12. Webster KE, Walters S, Kohler RE, Mrkvan T, Boyman O, Surh $\mathrm{CD}$, et al. In vivo expansion of $\mathrm{T}$ reg cells with IL-2-mAb complexes: induction of resistance to EAE and long-term acceptance of islet allografts without immunosuppression. J Exp Med. 2009;206(4):751-60.

13. Tsang JY, Tanriver Y, Jiang S, Leung E, Ratnasothy K, Lombardi G, et al. Indefinite mouse heart allograft survival in recipient treated with $\mathrm{CD} 4(+) \mathrm{CD} 25(+)$ regulatory $\mathrm{T}$ cells with indirect allospecificity and short term immunosuppression. Transpl Immunol. 2009;21(4):203-9.

14. Sykes M. Mixed chimerism and transplant tolerance. Immunity. 2001;14(4):417-24.

15. Kitchens WH, Adams AB. Nonhuman primate models of transplant tolerance: closer to the holy grail. Curr Opin Organ Transplant. 2016;21(1):59-65. https://doi.org/10.1097/MOT. 0000000000000271 . This review nicely summarizes published methods of transplantation tolerance induction in non-human primates including depletional techniques, induction of mixed hematopoietic chimerism, costimulation blockade, and adoptive transfer of tolerogenic cell populations.

16. Chong AS, Alegre ML, Miller ML, Fairchild RL. Lessons and limits of mouse models. Cold Spring Harb Perspect Med. 2013;3(12):a015495. https://doi.org/10.1101/cshperspect.a015495.

17. Adams AB, Williams MA, Jones TR, Shirasugi N, Durham MM, Kaech SM, et al. Heterologous immunity provides a potent barrier to transplantation tolerance. J Clin Invest. 2003;111(12):1887-95.

18.• Beura LK, Hamilton SE, Bi K, Schenkel JM, Odumade OA, Casey $\mathrm{KA}$, et al. Normalizing the environment recapitulates adult human immune traits in laboratory mice. Nature. 2016;532(7600):512-6. https://doi.org/10.1038/nature17655. This work highlights the effects of enviroment on the immune response and the advantages of non-SPF mice when it comes to clinical translation of animal studies.

19. Williams MA, Trambley J, Ha J, Adams AB, Durham MM, Rees P, et al. Genetic characterization of strain differences in the ability to mediate CD40/CD28-independent rejection of skin allografts. J Immunol. 2000;165(12):6849-57.
20.• Pilat N, Mahr B, Unger L, Hock K, Schwarz C, Farkas A, et al. Incomplete clonal deletion as prerequisite for tissue-specific minor antigen tolerization. JCI Insight. 2016;1(7):e85911. https://doi.org/ $10.1172 /$ jci.insight. 85911 . This paper shows that combined BMT and adoptive Treg transfer prevents chronic rejection by active intragraft regulation.

21. Bigenzahn S, Pree I, Klaus C, Pilat N, Mahr B, Schwaiger E, et al. Minor antigen disparities impede induction of long lasting chimerism and tolerance through bone marrow transplantation with costimulation blockade. J Immunol Res. 2016;2016:8635721. https://doi.org/10.1155/2016/8635721.

22. Wekerle T, Sayegh MH, Hill J, Zhao Y, Chandraker A, Swenson $\mathrm{KG}$, et al. Extrathymic $\mathrm{T}$ cell deletion and allogeneic stem cell engraftment induced with costimulatory blockade is followed by central T cell tolerance. J Exp Med. 1998;187(12):2037-44.

23. Boumpas DT, Furie R, Manzi S, Illei GG, Wallace DJ, Balow JE, et al. A short course of BG9588 (anti-CD40 ligand antibody) improves serologic activity and decreases hematuria in patients with proliferative lupus glomerulonephritis. Arthritis Rheum. 2003;48(3):719-27. https://doi.org/10.1002/art.10856.

24. Kawai T, Andrews D, Colvin RB, Sachs DH, Cosimi AB. Thromboembolic complications after treatment with monoclonal antibody against CD40 ligand. Nat Med. 2000;6(2):114.

25. Sidiropoulos PI, Boumpas DT. Lessons learned from anti-CD40L treatment in systemic lupus erythematosus patients. Lupus. 2004;13(5):391-7.

26. Zhang T, Pierson RN 3rd, Azimzadeh AM. Update on CD40 and CD154 blockade in transplant models. Immunotherapy. 2015;7(8): 899-911. https://doi.org/10.2217/IMT.15.54.

27. Xie JH, Yamniuk AP, Borowski V, Kuhn R, Susulic V, Rex-Rabe S, et al. Engineering of a novel anti-CD40L domain antibody for treatment of autoimmune diseases. J Immunol. 2014;192(9):4083-92. https://doi.org/10.4049/jimmunol.1303239.

28. Pilat N, Wekerle T. Transplantation tolerance through mixed chimerism. Nat Rev. 2010;6(10):594-605. https://doi.org/10. 1038/nrneph.2010.110.

29. Speiser DE, Roosnek E, Jeannet M, Zinkernagel RM. T-cell immunoincompetence in allogeneic chimerism. N Engl J Med. 1992;326(15):1028-9. https://doi.org/10.1056/ NEJM199204093261515.

30. Bigenzahn S, Blaha P, Koporc Z, Pree I, Selzer E, Bergmeister H, et al. The role of non-deletional tolerance mechanisms in a murine model of mixed chimerism with costimulation blockade. Am J Transplant. 2005;5(6):1237-47.

31. Hock K, Mahr B, Schwarz C, Wekerle T. Deletional and regulatory mechanisms coalesce to drive transplantation tolerance through mixed chimerism. Eur J Immunol. 2015;45(9):2470-9. https://doi. org/10.1002/eji.201545494.

32. Wekerle T, Kurtz J, Ito H, Ronquillo JV, Dong V, Zhao G, et al. Allogeneic bone marrow transplantation with co-stimulatory blockade induces macrochimerism and tolerance without cytoreductive host treatment. Nat Med. 2000;6(4):464-9.

33. Durham MM, Bingaman AW, Adams AB, Ha J, Waitze SY, Pearson TC, et al. Cutting edge: administration of anti-CD40 ligand and donor bone marrow leads to hemopoietic chimerism and donor-specific tolerance without cytoreductive conditioning. J Immunol. 2000;165(1):1-4.

34. Cippa PE, Gabriel SS, Chen J, Bardwell PD, Bushell A, Guimezanes A, et al. Targeting apoptosis to induce stable mixed hematopoietic chimerism and long-term allograft survival without myelosuppressive conditioning in mice. Blood. 2013;122(9): 1669-77. https://doi.org/10.1182/blood-2012-09-453944.

35. Pilat N, Baranyi U, Klaus C, Jaeckel E, Mpofu N, Wrba F, et al. Tregtherapy allows mixed chimerism and transplantation tolerance without cytoreductive conditioning. Am J Transplant. 2010;10(4):751-62. 
36. Pilat N, Farkas AM, Mahr B, Schwarz C, Unger L, Hock K, et al. Tregulatory cell treatment prevents chronic rejection of heart allografts in a murine mixed chimerism model. J Heart Lung Transplant. 2014;33(4):429-37. https://doi.org/10.1016/j.healun.2013.11.004.

37. Gabriel SS, Bon N, Chen J, Wekerle T, Bushell A, Fehr T, et al. Distinctive expression of $\mathrm{Bcl}-2$ factors in regulatory $\mathrm{T}$ cells determines a pharmacological target to induce immunological tolerance. Front Immunol. 2016;7:73. https://doi.org/10.3389/fimmu.2016. 00073. In this work, the authors could show that targeting apoptosis causes selective deletion of effector $T$ cells and enrichment in Tregs to prevent allograft rejection.

38. Joffre O, Santolaria T, Calise D, Al Saati T, Hudrisier D, Romagnoli $\mathrm{P}$, et al. Prevention of acute and chronic allograft rejection with CD4+CD25+Foxp3+ regulatory T lymphocytes. Nat Med. 2008;14(1):88-92.

39. Taylor PA, Panoskaltsis-Mortari A, Swedin JM, Lucas PJ, Gress RE, Levine BL, et al. L-selectin(hi) but not the L-selectin(lo) CD4+25+ T-regulatory cells are potent inhibitors of GVHD and BM graft rejection. Blood. 2004;104(12):3804-12.

40. Hanash AM, Levy RB. Donor CD4+CD25+ T cells promote engraftment and tolerance following MHC-mismatched hematopoietic cell transplantation. Blood. 2005;105(4):1828-36. https://doi. org/10.1182/blood-2004-08-3213.

41. Pilat N, Klaus C, Gattringer M, Jaeckel E, Wrba F, Golshayan D, et al. Therapeutic efficacy of polyclonal tregs does not require rapamycin in a low-dose irradiation bone marrow transplantation model. Transplantation. 2011;92(3):280-8. https://doi.org/10.1097/ TP.0b013e3182241133.

42. Al-Adra DP, Anderson CC. Mixed chimerism and split tolerance: mechanisms and clinical correlations. Chimerism. 2011;2(4):89-101. https://doi.org/10.4161/chim.2.4.19017 2011CHIMERISM0075R [pii].

43. Pasquet L, Joffre O, Santolaria T, van Meerwijk JP. Hematopoietic chimerism and transplantation tolerance: a role for regulatory $\mathrm{T}$ cells. Front Immunol. 2011;2:80. https://doi.org/10.3389/fimmu.2011.00080.

44. Dey B, Sykes M, Spitzer TR. Outcomes of recipients of both bone marrow and solid organ transplants. A review. Medicine. 1998;77(5):355-69.

45. Schwarz C, Lawitschka A, Bohmig GA, Dauber EM, Greinix H, Kozakowski N, et al. Kidney transplantation with corticosteroids alone after haploidentical HSCT from the same donor. Transplantation. 2016;29:29.

46. Kawai T, Cosimi AB, Spitzer TR, Tolkoff-Rubin N, Suthanthiran $\mathrm{M}$, Saidman SL, et al. HLA-mismatched renal transplantation without maintenance immunosuppression. N Engl J Med. 2008;358(4): 353-61. https://doi.org/10.1056/NEJMoa071074.

47. Kawai T, Sachs DH, Sykes M, Cosimi AB, Immune Tolerance N. HLA-mismatched renal transplantation without maintenance immunosuppression. N Engl J Med. 2013;368(19):1850-2. https:// doi.org/10.1056/NEJMc1213779.

48.• Kawai T, Sachs DH, Sprangers B, Spitzer TR, Saidman SL, Zorn E, et al. Long-term results in recipients of combined HLA-mismatched kidney and bone marrow transplantation without maintenance immunosuppression. Am J Transplant. 2014;14(7):1599-611. https:// doi.org/10.1111/ajt.12731. This work reports on the long-term results after combined $\mathrm{BM}$ and kidney transplantation without maintenance immunosuppression. Long-term stable allograft survival could be achieved following transient chimerism.

49. Scandling JD, Busque S, Dejbakhsh-Jones S, Benike C, Millan MT, Shizuru JA, et al. Tolerance and chimerism after renal and hematopoietic-cell transplantation. N Engl J Med. 2008;358(4):362-8.

50. Scandling JD, Busque S, Dejbakhsh-Jones S, Benike C, Sarwal M, Millan MT, et al. Tolerance and withdrawal of immunosuppressive drugs in patients given kidney and hematopoietic cell transplants. Am J Transplant. 2012;12(5):1133-45. https://doi.org/10.1111/j. 1600-6143.2012.03992.x.
51. Scandling JD, Busque S, Shizuru JA, Lowsky R, Hoppe R, DejbakhshJones S, et al. Chimerism, graft survival, and withdrawal of immunosuppressive drugs in HLA matched and mismatched patients after living donor kidney and hematopoietic cell transplantation. Am J Transplant. 2015;15(3):695-704. https://doi.org/10.1111/ajt.13091.

52. Leventhal J, Abecassis M, Miller J, Gallon L, Ravindra K, Tollerud DJ, et al. Chimerism and tolerance without GVHD or engraftment syndrome in HLA-mismatched combined kidney and hematopoietic stem cell transplantation. Sci Transl Med. 2012;4(124):124ra28. https://doi. org/10.1126/scitranslmed.3003509.

53. Leventhal J, Abecassis M, Miller J, Gallon L, Tollerud D, Elliott MJ, et al. Tolerance induction in HLA disparate living donor kidney transplantation by donor stem cell infusion: durable chimerism predicts outcome. Transplantation. 2013;95(1):169-76. https://doi.org/ 10.1097/TP.0b013e3182782fc1.

54. Leventhal JR, Elliott MJ, Yolcu ES, Bozulic LD, Tollerud DJ, Mathew JM et al. Immune reconstitution/immunocompetence in recipients of kidney plus hematopoietic stem/facilitating cell transplants. Transplantation. 2015. https://doi.org/10.1097/TP. 0000000000000605.

55. Oura T, Cosimi AB, Kawai T. Chimerism-based tolerance in organ transplantation: preclinical and clinical studies. Clin Exp Immunol. 2017. https://doi.org/10.1111/cei.12969.

56. Bühler LH, Spitzer TR, Sykes M, Sachs DH, Delmonico FL, Tolkoff-Rubin N, et al. Induction of kidney allograft tolerance after transient lymphohematopoietic chimerism in patients with multiple myeloma and end-stage renal disease. Transplantation. 2002;74(10):1405-9.

57. Fudaba Y, Spitzer TR, Shaffer J, Kawai T, Fehr T, Delmonico F, et al. Myeloma responses and tolerance following combined kidney and nonmyeloablative marrow transplantation: in vivo and in vitro analyses. Am J Transplant. 2006;6(9):2121-33.

58. Spitzer TR, Delmonico F, Tolkoff-Rubin N, McAfee S, Sackstein $\mathrm{R}$, Saidman S, et al. Combined histocompatibility leukocyte antigen-matched donor bone marrow and renal transplantation for multiple myeloma with end stage renal disease: the induction of allograft tolerance through mixed lymphohematopoietic chimerism. Transplantation. 1999;68(4):480-4.

59. Spitzer TR, Sykes M, Tolkoff-Rubin N, Kawai T, McAfee SL, Dey $\mathrm{BR}$, et al. Long-term follow-up of recipients of combined human leukocyte antigen-matched bone marrow and kidney transplantation for multiple myeloma with end-stage renal disease. Transplantation. 2011;91(6):672-6. https://doi.org/10.1097/TP. 0b013e31820a3068.

60. Morris H, DeWolf S, Robins H, Sprangers B, SA LC, Shonts BA, et al. Tracking donor-reactive T cells: evidence for clonal deletion in tolerant kidney transplant patients. Sci Transl Med. 2015;7(272): 272ra10. https://doi.org/10.1126/scitranslmed.3010760. The authors established an assay to specifically track donorreactive $T$ cell clones to analyse clonal deletion in patients receiving combined $\mathrm{BM}$ and kidney transplantation.

61.• Sprangers B, DeWolf S, Savage TM, Morokata T, Obradovic A, LoCascio SA et al. Origin of enriched regulatory T cells in patients receiving combined kidney-bone marrow transplantation to induce transplantation tolerance. Am J Transplant. 2017. https://doi.org/10. 1111/ajt.14251. The authors examined tolerance mechanisms in tolerant patients after combined BM and kidney transplantation by analyzing $T$ cells in biopsy samples.

62. Granados JM, Benichou G, Kawai T. Hematopoietic stem cell infusion/transplantation for induction of allograft tolerance. Curr Opin Organ Transplant. 2015;20(1):49-56. https://doi.org/10. 1097/MOT.0000000000000159.

63. Umemura A, Morita H, Li XC, Tahan S, Monaco AP, Maki T. Dissociation of hemopoietic chimerism and allograft tolerance after allogeneic bone marrow transplantation. J Immunol. 2001;167(6):3043-8. 
64. Xu A, Liu Y, Chen W, Wang J, Xue Y, Huang F, et al. TGF-betainduced regulatory $\mathrm{T}$ cells directly suppress $\mathrm{B}$ cell responses through a noncytotoxic mechanism. J Immunol. 2016; https://doi. org/10.4049/jimmunol.1501740.

65. Kawai T, Sogawa H, Boskovic S, Abrahamian G, Smith RN, Wee SL, et al. CD154 blockade for induction of mixed chimerism and prolonged renal allograft survival in nonhuman primates. Am J Transplant. 2004;4(9):1391-8.

66. Kawai T, Cosimi AB, Colvin RB, Powelson J, Eason J, Kozlowski $\mathrm{T}$, et al. Mixed allogeneic chimerism and renal allograft tolerance in cynomolgus monkeys. Transplantation. 1995;59(2):256-62.

67. Yeung MY, McGrath MM, Nakayama M, Shimizu T, Boenisch O, Magee CN, et al. Interruption of dendritic cell-mediated TIM-4 signaling induces regulatory $\mathrm{T}$ cells and promotes skin allograft survival. J Immunol. 2013;191(8):4447-55. https://doi.org/10. 4049/jimmunol.1300992.

68. Sakaguchi S, Sakaguchi N, Asano M, Itoh M, Toda M. Immunologic self-tolerance maintained by activated $\mathrm{T}$ cells expressing IL-2 receptor alpha-chains (CD25). Breakdown of a single mechanism of self-tolerance causes various autoimmune diseases. J Immunol. 1995;155(3):1151-64.

69. Karim M, Feng G, Wood KJ, Bushell AR. CD25+CD4+ regulatory $\mathrm{T}$ cells generated by exposure to a model protein antigen prevent allograft rejection: antigen-specific reactivation in vivo is critical for bystander regulation. Blood. 2005;105(12):4871-7. https://doi.org/ 10.1182/blood-2004-10-3888

70. Nadig SN, Wieckiewicz J, DC W, Warnecke G, Zhang W, Luo S, et al. In vivo prevention of transplant arteriosclerosis by ex vivoexpanded human regulatory T cells. Nat Med. 2010;16(7):809-13. https://doi.org/10.1038/nm.2154.

71. Chai JG, Xue S, Coe D, Addey C, Bartok I, Scott D, et al. Regulatory $\mathrm{T}$ cells, derived from naive CD4+CD25- T cells by in vitro Foxp3 gene transfer, can induce transplantation tolerance. Transplantation. 2005;79:1310-6.

72. Tsang JY, Tanriver Y, Jiang S, Xue SA, Ratnasothy K, Chen D, et al. Conferring indirect allospecificity on CD4+CD25+ Tregs by TCR gene transfer favors transplantation tolerance in mice. J Clin Invest. 2008;118(11):3619-28.

73. Trzonkowski P, Bacchetta R, Battaglia M, Berglund D, Bohnenkamp HR, Ten Brinke A, et al. Hurdles in therapy with regulatory T cells. Sci Transl Med. 2015;7(304):304ps18. https:// doi.org/10.1126/scitranslmed.aaa7721.

74. Todo S, Yamashita K, Goto R, Zaitsu M, Nagatsu A, Oura T, et al. A pilot study of operational tolerance with a regulatory T-cell-based cell therapy in living donor liver transplantation. Hepatology. 2016;64(2):632-43. https://doi.org/10.1002/hep.28459. This is the first clinical study reporting on adoptive Treg transfer for tolerance induction in organ transplantation.

75. Sho M, Kishimoto K, Harada H, Livak M, Sanchez-Fueyo A, Yamada $\mathrm{A}$, et al. Requirements for induction and maintenance of peripheral tolerance in stringent allograft models. Proc Natl Acad Sci U S A. 2005;102(37):13230-5. https://doi.org/10.1073/pnas.0505070102.

76. Fuchs EJ. Transplantation tolerance: from theory to clinic. Immunol Rev. 2014;258(1):64-79. https://doi.org/10.1111/imr.12154.
77. Legoux FP, Lim JB, Cauley AW, Dikiy S, Ertelt J, Mariani TJ, et al. CD4+ T cell tolerance to tissue-restricted self antigens is mediated by antigen-specific regulatory $\mathrm{T}$ cells rather than deletion. Immunity. 2015;43(5):896-908.

78. Pilat N, Wekerle T. Combining Treg therapy with mixed chimerism: getting the best of both worlds. Chimerism. 2010;1(1):1-4.

79. Joffre O, Gorsse N, Romagnoli P, Hudrisier D, van Meerwijk JP. Induction of antigen-specific tolerance to bone marrow allografts with CD4+CD25+ T lymphocytes. Blood. 2004;103(11):4216-21.

80. Lin JY, Tsai FC, Wallace CG, Huang WC, Wei FC, Liao SK. Combined treatment with regulatory $\mathrm{T}$ cells and vascularized bone marrow transplantation creates mixed chimerism and induces donor-specific tolerance to vascularized composite allografts without cytoreductive conditioning. J Surg Res. 2012;178(2):974-81. https://doi.org/10.1016/j.jss.2012.06.061.

81. Hongo D, Tang X, Dutt S, Nador RG, Strober S. Interactions between NKT cells and Tregs are required for tolerance to combined bone marrow and organ transplants. Blood. 2012;119(6):1581-9. https://doi.org/10.1182/blood-2011-08-371948.

82. Im KI, Park MJ, Kim N, Lim JY, Park HS, Lee SH, et al. Induction of mixed chimerism using combinatory cell-based immune modulation with mesenchymal stem cells and regulatory T cells for solidorgan transplant tolerance. Stem Cells Dev. 2014;23(19):2364-76. https://doi.org/10.1089/scd.2013.0617.

83. Pilat N, Klaus C, Hock K, Baranyi U, Unger L, Mahr B, et al. Polyclonal recipient nTregs are superior to donor or third-party tregs in the induction of transplantation tolerance. J Immunol Res. 2015;2015:562935. https://doi.org/10.1155/2015/562935.

84. Ruiz P, Maldonado P, Hidalgo Y, Sauma D, Rosemblatt M, Bono $\mathrm{MR}$, et al. Cells allow the generation of mixed chimerism and transplant tolerance. Front Immunol. 2015;6:596. https://doi.org/ 10.3389/fimmu.2015.00596.

85.• Duran-Struuck R, Sondermeijer HP, Buhler L, Alonso-Guallart P, Zitsman J, Kato Y, et al. Effect of ex vivo-expanded recipient regulatory $t$ cells on hematopoietic chimerism and kidney allograft tolerance across MHC barriers in cynomolgus macaques. Transplantation. 2017;101(2):274-83. https://doi.org/10.1097/TP. 0000000000001559 . This study provides proof-of-principle that Treg co-transfer can promote BM engraftment and prevent allograft rejection in a non-human primate model.

86. Jaeckel E, von Boehmer H, Manns MP. Antigen-specific FoxP3transduced T-cells can control established type 1 diabetes. Diabetes. 2005;54(2):306-10.

87. Golshayan D, Jiang S, Tsang J, Garin MI, Mottet C, Lechler RI. In vitro-expanded donor alloantigen-specific $\mathrm{CD} 4+\mathrm{CD} 25+$ regulatory $\mathrm{T}$ cells promote experimental transplantation tolerance. Blood. 2007;109(2):827-35.

88. Thornton AM, Shevach EM. Suppressor effector function of CD4+ CD25+ immunoregulatory $\mathrm{T}$ cells is antigen nonspecific. $\mathrm{J}$ Immunol. 2000;164(1):183-90.

89. Mahr B, Unger L, Hock K, Pilat N, Baranyi U, Schwarz C, et al. IL2/alpha-IL-2 complex treatment cannot be substituted for the adoptive transfer of regulatory $t$ cells to promote bone marrow engraftment. PLoS One. 2016;11(1):e0146245. https://doi.org/10.1371/ journal.pone.0146245. 